\title{
Beta-asarone, a major component of Acorus tatarinowii Schott, attenuates focal cerebral ischemia induced by middle cerebral artery occlusion in rats
}

Yuan-Xiao Yang ${ }^{1}$, Yi-Tao Chen ${ }^{1}$, Xiao-Jie Zhou' ${ }^{1}$, Chun-Lan Hong ${ }^{1}$, Chang-Yu Li ${ }^{1 *}$ and Jian-You Guo ${ }^{2^{*}}$

\begin{abstract}
Background: Ischemic hypoxic brain injury often causes irreversible brain damage. The lack of effective and widely applicable pharmacological treatments for ischemic stroke patients may explain a growing interest in traditional medicines. $\beta$-Asarone, which has significant pharmacological effects on the central nervous system (CNS), was used in the prevention of cerebral ischemia in this paper.

Methods: The right middle cerebral artery occlusion model was used in the study. The effects of $\beta$-Asarone on mortality rate, neurobehavior, grip strength, lactate dehydrogenase, glutathione content, Lipid peroxidation, glutathione peroxidase activity, glutathione reductase activity, catalase activity, $\mathrm{Na}^{+}-\mathrm{K}^{+}$-ATPase activity and glutathione $S$ transferase activity in a rat model were studied respectively.

Results: $\beta$-Asarone significantly improved the neurological outcome after cerebral ischemia and reperfusion in terms of neurobehavioral function in rats. Meanwhile, supplementation of $\beta$-Asarone significantly boosted the defense mechanism against cerebral ischemia via increasing antioxidants activity related to lesion pathogenesis. Restoration of the antioxidant homeostasis in the brain after reperfusion may help the brain recover from ischemic injury.

Conclusions: These experimental results suggest that complement $\beta$-Asarone is protective against cerebral ischemia in specific way. The administration of $\beta$-Asarone could reduce focal cerebral ischemic/reperfusion injury. The Mechanism of $\beta$-Asarone in protection of cerebral ischemia was via increasing antioxidants activity related to lesion pathogenesis.
\end{abstract}

\section{Background}

Ischemic hypoxic brain injury often causes irreversible brain damage. The cascade of events leading to neuronal injury and death in ischemia includes the release of cytokines and free radicals, and induction of inflammation, apoptosis, and excitotoxicity [1]. Reperfusion of ischemic areas could exacerbate ischemic brain damage through the generation of reactive oxygen species. The lack of effective and widely applicable pharmacological treatments for ischemic stroke patients may explain a growing interest in traditional medicines.

Acorus tatarinowii Schott is native to Central Asia, North America and Eastern Europe [2]. B-Asarone

\footnotetext{
* Correspondence: lichangyuzj@126.com; guojianyou@126.com

'Zhejiang Chinese Medical University, Hangzhou 310053, PR China

${ }^{2}$ Key Laboratory of Mental Health, Institute of Psychology, Chinese Academy of Sciences, Beijing 100101, PR China
}

(c) 2013 Yang et al.; licensee BioMed Central Ltd. This is an Open Access article distributed under the terms of the Creative Commons Attribution License (http://creativecommons.org/licenses/by/2.0), which permits unrestricted use, distribution, and reproduction in any medium, provided the original work is properly cited. (cis-2,4,5-trimethoxy-1-allyl phenyl), which can affect the central nervous system (CNS) [3-6], is a major component of Acorus tatarinowii Schott. $\beta$-Asarone could pass the blood-brain barrier (BBB) and thus enter the brain [7]. It has been reported that $\beta$-Asarone (Figure 1) could attenuate neuronal apoptosis in rat hippocampus and might be a potential candidate for development as a therapeutic agent to manage cognitive impairment associated with conditions such as Alzheimer's disease [8,9]. Other authors found $\beta$-Asarone could reduce the toxicity of excitatory amino acids and increase the expression of c-fos in the epileptic rat brain [10]. In addition, $\beta$-Asarone could reduce the injuries of blood vessel endothelium and nerve cells of the cortex [11] and improve the cognitive function of the beta-amyloid hippocampus injection rats [12]. 


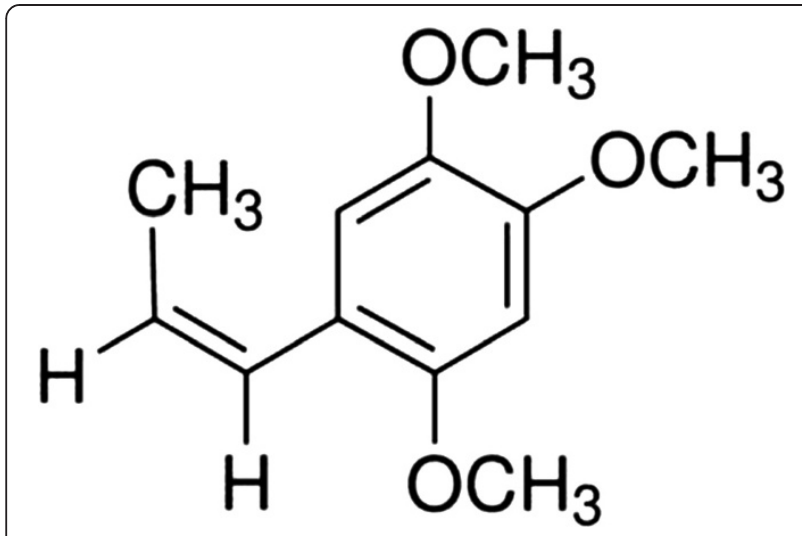

Figure 1 The chemical structure of $\beta$-Asarone.

Thus, we hypothesize that $\beta$-Asarone possess protective effect of against ischemia-induced brain infarction. The present study was aimed to investigate the effects of $\beta$-Asarone on mortality rate, neurobehavior, grip strength, lactate dehydrogenase, glutathione content, Lipid Peroxidation, glutathione peroxidase activity, glutathione reductase activity, catalase activity, $\mathrm{Na}^{+}-\mathrm{K}^{+}$-ATPase activity and glutathione $\mathrm{S}$ transferase activity in a rat model.

\section{Methods}

\section{Animals}

Healthy adult Wistar rats (2 months old and weighing $225 \pm 25 \mathrm{~g})$ were used in the study. This study was approved by Zhejiang Chinese Medical University's ethics committee, and all procedures complied with the guidance set out in the Guidelines for Caring for Experimental Animals published by the Ministry of Science and Technology of the People's Republic of China. Every care was taken to minimize discomfort, distress, and pain.

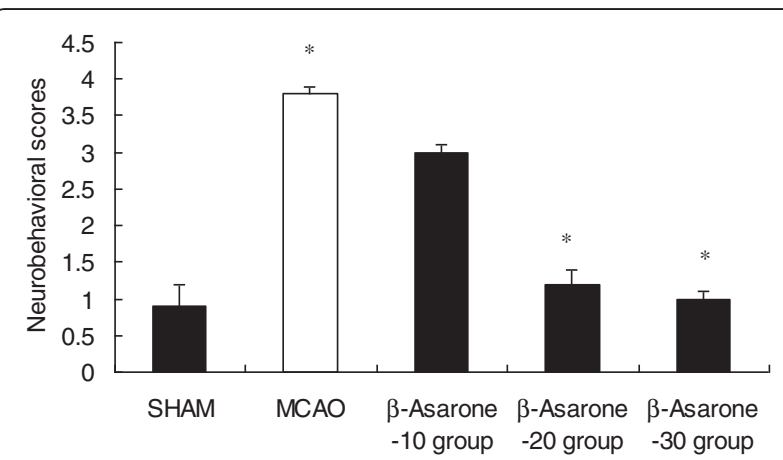

Figure 2 Effect of $\beta$-Asarone on the development of behavioral abnormalities after middle cerebral artery occlusion. Values are shown as means \pm SEM. ${ }^{*} p<0.05$ vs. MCAO group, ${ }^{* *} p<0.01$ vs. MCAO group. $\left(F_{\text {SHAM }}=17.642, \mathrm{df}_{\text {SHAM }}=11, \mathrm{P}_{\text {SHAM }}=0.001, \mathrm{~F}_{\beta-\text { Asarone- } 10}=2.252, \mathrm{df}_{\beta-}\right.$ Asarone-10 $=11, \mathrm{p}_{\beta \text {-Asarone-10 }}=0.162, \mathrm{~F}_{\beta \text {-Asarone-20 }}=16.396, \mathrm{df}_{\beta \text {-Asarone-20 }}=11$, $\mathrm{p}_{\beta \text {-Asarone-20 }}=0.01, \mathrm{~F}_{\beta \text {-Asarone }-30}=22.738, \mathrm{df}_{\text {SHAM }}=11, \mathrm{p}_{\mathrm{SHAM}}=0.02$ ).
Table 1 Effect of $\boldsymbol{\beta}$-Asarone on basal grip strength

\begin{tabular}{|c|c|c|c|c|}
\hline Different groups & $\begin{array}{l}\text { Grip strength } \\
\text { (Kg Units) }\end{array}$ & F-values & df-values & p-values \\
\hline MCAO group & $0.506 \pm 0.002^{b}$ & & & \\
\hline SHAM group & $0.888 \pm 0.008^{\mathrm{a}}$ & 0.155 & 11 & 0.002 \\
\hline$\beta$-Asarone-10 group & $0.560 \pm 0.022^{b}$ & 0.154 & 11 & 0.005 \\
\hline$\beta$-Asarone-20 group & $0.788 \pm 0.004^{a}$ & 0.145 & 11 & 0.001 \\
\hline$\beta$-Asarone-30 group & $0.799 \pm 0.020^{\mathrm{a}}$ & 2.974 & 11 & 0.004 \\
\hline
\end{tabular}

Values are shown as means \pm SEM. The different letters in the same column indicate a statistical difference ( $p<0.01$ vs. MCAO group).

\section{Chemicals}

Acorus tatarinowii Schott were collected in Bozhou, China. Dr. Changyu Li at the Zhejiang Chinese Medical University established the identity of these species. $\beta$-Asarone was obtained as reported by Zanoli et al. [13]. Purity up to $99.55 \%$ was confirmed by gas chromatography-mass spectrometry (GC-MS), infrared spectrum (IR) and nuclear magnetic resonance (NMR) detection. The voucher specimen (No. SAC/20120412) was deposited at the Herbarium of the College of Pharmacology, Zhejiang Chinese Medical University, China.

\section{Experimental design}

The animals were separated into five groups of ten rats each. The first group served as sham (SHAM). The second group was the ischemic group (MCAO). Group I and group II were treated orally by distilled water for 30 days respectively. Group III ( $\beta$-Asarone-10), Group IV ( $\beta$-Asarone-20) and Group V $(\beta$-Asarone-30) were treated orally by $\beta$-Asarone $(10,20$ and $30 \mathrm{mg} / \mathrm{kg} /$ day, respectively) for 30 days followed by middle cerebral artery occlusion (MCAO) induced cerebral ischemia.

The right $\mathrm{MCAO}$ was performed using an intraluminal filament model and the method described by Liu et al. [14]. In brief, the rats were anesthetized with chloral hydrate (400 $\mathrm{mg} / \mathrm{kg}$, i.p.), a 4-0 nylon monofilament with a blunt end was introduced into the external carotid artery (ECA) and advanced into the middle cerebral artery via the internal carotid artery (ICA) (17-20 mm), until a slight resistance was felt. Successful occlusion was confirmed by an $87-90 \%$ reduction in cerebral blood flow (CBF), as measured by laser-Doppler flowmetry [15].

Table 2 Effect of $\beta$-Asarone on serum LDH levels

\begin{tabular}{lllll}
\hline Different groups & LDH (IU/L) & F-values & df-values & p-values \\
\hline MCAO group & $156.200 \pm 3.331$ & & & \\
SHAM group & $80.200 \pm 1.233^{* * *}$ & 6.555 & 5.183 & 0.000 \\
$\beta$-Asarone-10 group & $166.600 \pm 2.111$ & 7.190 & 11 & 0.118 \\
$\beta$-Asarone-20 group & $126.630 \pm 3.111^{* *}$ & 7.490 & 5.063 & 0.001 \\
$\beta$-Asarone-30 group & $111.231 \pm 2.111^{* *}$ & 0.425 & 11 & 0.005 \\
\hline
\end{tabular}

Values are shown as means \pm SEM. ${ }^{* *} p<0.01$ vs. MCAO group, ${ }^{* * *} p<0.001$ vs. MCAO group. 
Table 3 Effect of $\beta$-Asarone on Hippocampus GSH

\begin{tabular}{lllll}
\hline $\begin{array}{l}\text { Different } \\
\text { groups }\end{array}$ & $\begin{array}{l}\text { Hippocampus GSH } \\
\text { (nmol GSH/mg protein) }\end{array}$ & F-values & df-values & p-values \\
\hline $\begin{array}{l}\text { MCAO } \\
\text { group }\end{array}$ & $0.760 \pm 0.035$ & & & \\
$\begin{array}{l}\text { SHAM } \\
\text { group }\end{array}$ & $2.398 \pm 0.013^{* *}$ & 7.993 & 6.286 & 0.009 \\
$\begin{array}{l}\beta \text {-Asarone- } \\
10 \text { group }\end{array}$ & $1.115 \pm 0.005$ & 1.860 & 11 & 0.379 \\
$\begin{array}{l}\text { B-Asarone- } \\
20 \text { group }\end{array}$ & $2.565 \pm 0.015^{* *}$ & 6.536 & 6.400 & 0.008 \\
$\begin{array}{l}\beta \text {-Asarone- } \\
30 \text { group }\end{array}$ & $1.333 \pm 0.002^{*}$ & & & \\
\hline
\end{tabular}

Values are shown as means \pm SEM. ${ }^{*} p<0.05$ vs. MCAO group, ${ }^{* *} p<0.01$ vs. MCAO group.

Two hours after the induction of ischemia, the filament was slowly withdrawn and the animals were returned to their cages for a period of 22 hours of reperfusion. Throughout the procedure, the body temperature was maintained at $37^{\circ} \mathrm{C}$, with a thermostatically controlled infrared lamp. In sham rats, the ECA was surgically prepared for the insertion of the filament, but the filament was not inserted. The final number of rats was as follows: SHAM group $n=10$; MCAO group $n=6$; $\beta$-Asarone-10 group $n=8 ; \beta$-Asarone-20 group $n=8$ and $\beta$-Asarone-30 group $\mathrm{n}=9$.

\section{Neurobehavioral test}

The sensorimotor integrity was conducted to assess the neurobehavior at $24 \mathrm{~h}$ after MCAO in rats [16]. Five categories of motor neurological findings were scored: 0 , no observable deficit; 1 , forelimb flexion; 2, forelimb flexion and decreased resistance to lateral push; 3, forelimb flexion, decreased resistance to lateral push and unilateral circling; 4, forelimb flexion, unable or difficult to ambulate. Animals that showed the features of the higher scores also showed all the features of the lower grades.

Table 4 Effect of $\beta$-Asarone on Cerebral cortex GSH

\begin{tabular}{lllll}
\hline $\begin{array}{l}\text { Different } \\
\text { groups }\end{array}$ & $\begin{array}{l}\text { Cerebral cortex GSH } \\
\text { (nmol GSH/mg protein) }\end{array}$ & F-values & df-values & p-values \\
\hline $\begin{array}{l}\text { MCAO } \\
\text { group }\end{array}$ & $1.112 \pm 0.010$ & & & \\
$\begin{array}{l}\text { SHAM } \\
\text { group }\end{array}$ & $1.823 \pm 0.026^{*}$ & 4.193 & 11 & 0.017 \\
$\begin{array}{l}\beta \text {-Asarone- } \\
10 \text { group }\end{array}$ & $1.195 \pm 0.021$ & 4.043 & 11 & 0.336 \\
$\begin{array}{l}\text { B-Asarone- } \\
20 \text { group }\end{array}$ & $1.595 \pm 0.053^{*}$ & 3.306 & 11 & 0.026 \\
$\begin{array}{l}\beta \text {-Asarone- } \\
\text { 30 group }\end{array}$ & $1.395 \pm 0.011^{*}$ & 3.418 & 11 & 0.427 \\
\hline
\end{tabular}

Values are shown as means \pm SEM. ${ }^{*} p<0.05$ vs. MCAO group.
Table 5 Effect of $\beta$-Asarone on LPO level

\begin{tabular}{lllll}
\hline Different groups & $\begin{array}{l}\text { nmol LPO/g } \\
\text { protein }\end{array}$ & F-values & df-values & p-values \\
\hline MCAO group & $20.21 \pm 1.41$ & & & \\
SHAM group & $13.23 \pm 0.66^{* *}$ & 5.254 & 6.996 & 0.003 \\
$\begin{array}{l}\beta-A s a r o n e-10 \\
\text { group }\end{array}$ & $20.01 \pm 0.21$ & 19.460 & 5.010 & 0.846 \\
$\begin{array}{l}\beta-A s a r o n e-20 \\
\text { group }\end{array}$ & $15.32 \pm 0.11^{*}$ & 1.304 & 10 & 0.043 \\
$\begin{array}{l}\beta-A s a r o n e-30 \\
\text { group }\end{array}$ & $15.22 \pm 0.21^{*}$ & 1.305 & 10 & 0.042 \\
\hline $\begin{array}{l}\text { Values are shown as means } \pm \text { SEM. }{ }^{*} p<0.05 \text { vs. MCAO group, } \\
\text { MCAO group. }\end{array}$ &
\end{tabular}

\section{Grip strength study}

Grip strength in all the animals was measured for evaluation of neuromuscular strength, as described by Ali et al. [17]. The neuromuscular strength tests were carried out between 9:00 a.m. to 4:00 p.m. under standard laboratory conditions.

\section{Tissue preparation}

After grip strength measurement, blood samples were drawn from the tail vein from all the groups and serum was separated for biochemical estimations. Thereafter, the animals were sacrificed immediately and their brains were taken out to dissect the hippocampus (HIP). Postmitochondrial supernatant (PMS) obtained from 10\% homogenate of tissue was used for the estimation of various parameters related with oxidative stress.

\section{Biochemical estimations}

In serum, lactate dehydrogenase (LDH) was estimated using a method described by Khan et al. [18]. The PMS and HIP were used for the assay of glutathione (GSH) content, Lipid peroxidation (LPO), glutathione peroxidase (GPx) activity, glutathione reductase (GR) activity, catalase (CAT) activity, $\mathrm{Na}^{+}-\mathrm{K}^{+}$-ATPase activity and glutathione $\mathrm{S}$ transferase (GST) activity [19-24].

\section{Statistical analysis}

The data are expressed as mean \pm SEM. Statistical differences between means were determined by one-way

Table 6 Effect of $\beta$-Asarone on the activity of GPx

\begin{tabular}{lllll}
\hline Different groups & \multicolumn{1}{c}{$\mathbf{G P x}$} & F-values & df-values & $\mathbf{p}$-values \\
\hline MCAO & $8.11 \pm 0.42$ & & & \\
SHAM & $14.28 \pm 1.23^{* *}$ & 0.713 & 11 & 0.001 \\
$\beta$-Asarone-10 group & $9.11 \pm 1.22$ & 0.910 & 11 & 0.306 \\
$\beta$-Asarone-20 group & $12.06 \pm 1.22^{* *}$ & 3.556 & 11 & 0.006 \\
$\beta$-Asarone-30 group & $11.11 \pm 1.21^{*}$ & 0.053 & 11 & 0.04 \\
\hline
\end{tabular}

Values are shown as means \pm SEM. ${ }^{*} p<0.05$ vs. MCAO group, ${ }^{* *} p<0.01$ vs. MCAO group. 
Table 7 Effect of $\boldsymbol{\beta}$-Asarone on the activity of GR

\begin{tabular}{lllll}
\hline Different groups & GR & F-values & df-values & p-values \\
\hline MCAO & $20.80 \pm 2.10$ & & & \\
SHAM & $35.22 \pm 2.41^{* *}$ & 0.953 & 11 & 0.006 \\
$\beta$-Asarone-10 group & $21.11 \pm 2.12$ & 0.03 & 11 & 0.954 \\
$\beta$-Asarone-20 group & $30.01 \pm 2.12^{*}$ & 4.394 & 11 & 0.028 \\
$\beta$-Asarone-30 group & $25.22 \pm 2.01^{*}$ & 4.929 & 11 & 0.048
\end{tabular}

Values are shown as means \pm SEM. ${ }^{*} p<0.05$ vs. MCAO group, ${ }^{* *} p<0.01$ vs. MCAO group.

analysis of variance (ANOVA), followed by Dunnett $t$-test. The values of $P<0.05$ were considered as significant.

\section{Results and discussion}

In this study, the cerebroprotective effect of $\beta$-Asarone on ischemic neuronal damage was clearly demonstrated using focal ischemia model rats.

The behavioral tasks adopted in this study were designed to assess impairments consistent with the known functional architecture of the rat brain.

Twenty-four hours after MCAO in rats, neurological deficit scores were significantly reduced in $\beta$-Asarone20 -treated rats and $\beta$-Asarone-30-treated rats. The neurobehavior for the SHAM group was 0.9 (0.6-1.1), the MCAO group was 3.7 (2.6-5.3), the $\beta$-Asarone-10 group was 3.0 (2.2-4.1), the $\beta$-Asarone-20 group was 1.2 (1.0-4.1) and the $\beta$-Asarone-30 group was 1.0 (1.0-3.0). It is clear that the behavioral abnormality was significantly developed in the MCAO group as compared with the sham (Figure 2). In contrast, the $\beta$-Asarone-20 group and $\beta$-Asarone-30 group significantly suppressed the development of behavioral abnormality as compared with the MCAO group (Figure 2).

The grip strength in the SHAM group was found to be $0.888 \pm 0.008 \mathrm{~kg}$ units. A significant decrease in the grip strength was observed in the MCAO group $(0.506 \pm 0.002)$, as compared to the sham rats $(P<0.01)$. Both $\beta$-Asarone-20 and $\beta$-Asarone-30 treated rats showed a significant increase in grip strength, as compared to the MCAO group $(P<0.01)$ (Table 1$)$.

Increasing evidence has indicated that ischemia/reperfusion occurs due to oxidative stress that may potentiate

Table 8 Effect of $\beta$-Asarone on the activity of GST

\begin{tabular}{lllll}
\hline Different groups & GST & F-values & df-values & p-values \\
\hline MCAO & $10.17 \pm 1.10$ & & & \\
SHAM & $15.11 \pm 1.20^{* *}$ & 16.088 & 13 & 0.002 \\
$\beta$-Asarone-10group & $11.60 \pm 1.07$ & 9.946 & 10 & 0.680 \\
$\beta$-Asarone-20 group & $13.61 \pm 1.98^{* *}$ & 19.214 & 11 & 0.008 \\
$\beta$-Asarone-30group & $12.66 \pm 1.80^{*}$ & 20.293 & 12 & 0.029 \\
\hline
\end{tabular}

Values are shown as means \pm SEM. ${ }^{*} p<0.05$ vs. MCAO group, ${ }^{* *} p<0.01$ vs. MCAO group.
Table 9 Effect of $\beta$-Asarone on the activity of CAT

\begin{tabular}{lllll}
\hline Different groups & CAT & F-values & df-values & p-values \\
\hline MCAO & $4.20 \pm 0.03$ & & & \\
SHAM & $7.10 \pm 0.03^{*}$ & 7.196 & 12 & 0.010 \\
$\beta$-Asarone-10 group & $5.77 \pm 0.14$ & 3.917 & 10 & 0.076 \\
$\beta$-Asarone-20 group & $6.70 \pm 0.13^{*}$ & 6.977 & 11 & 0.02 \\
$\beta$-Asarone-30 group & $6.71 \pm 0.33^{*}$ & 6.858 & 11 & 0.024 \\
\hline
\end{tabular}

Values are shown as means \pm SEM. * $p<0.05$ vs. MCAO group.

ischemic injury [25]. Lactate dehydrogenase was measured to evaluate the role of antioxidative stress in the protection of $\beta$-Asarone. The serum LDH levels in SHAM group were found to be $80.200 \pm 1.233$ IU/L. A significant increase in the activity of LDH in serum was observed in MCAO group, as compared to the SHAM group; whereas, $\beta$-Asarone-20 and $\beta$-Asarone-30 treatment significantly resulted in decreased serum LDH levels when compared with MCAO group rats (Table 2).

Reduced glutathione (GSH) is one of the primary endogenous antioxidant defense systems in the brain, which removes hydrogen peroxide and lipid peroxides. Decline in GSH levels could either increase or reflect oxidative status [26,27]. Concentrations of GSH were lower in MCAO group than those in SHAM group (Tables 3 and 4). $\beta$-Asarone-20 treatment significantly increased the GSH.level. The same results did occur in the $\beta$-Asarone-30 group. It can be attributed to several factors such as cleavage GSH to cysteine, decrease in the synthesis of GSH and the formation of mixed disulfides, causing their cellular stores to be depleted [28].

The large numbers of polyunsaturated fatty acids make cell membranes particularly vulnerable to lipid peroxidation. The oxidation of polyunsaturated fatty acids alters the structure of the membrane with resultant changes in fluidity and permeability. Lipid peroxidation can also inhibit the function of membrane bound receptors and enzymes [29]. The level of LPO content adds to the proof of the increased peroxidative damage during cerebral ischemia. A significant increase in the content of LPO was observed in the MCAO group when compared with the SHAM group. In the $\beta$-Asarone-20 and $\beta$-Asarone-30

Table 10 Effect of $\beta$-Asarone on the activity of $\mathrm{Na}^{+} \mathrm{K}^{+}$ATPase

\begin{tabular}{lllll}
\hline Different groups & $\mathbf{N a}^{+} \mathbf{K}^{+} \mathbf{A T P a s e}$ & $\mathbf{F}$-values & $\mathbf{d f - v a l u e s}$ & $\mathbf{p}$-values \\
\hline MCAO & $2.11 \pm 0.23$ & & & \\
SHAM & $4.53 \pm 0.33^{* *}$ & 16.966 & 11 & 0.002 \\
$\beta$-Asarone-10group & $2.00 \pm 0.11$ & 0.176 & 11 & 0.684 \\
$\beta$-Asarone-20 group & $4.22 \pm 0.22^{*}$ & 17.700 & 11 & 0.001 \\
$\beta$-Asarone-30group & $4.16 \pm 0.33^{*}$ & 16.312 & 11 & 0.002 \\
\hline
\end{tabular}

Values are shown as means \pm SEM. ${ }^{*} p<0.05$ vs. MCAO group, ${ }^{* *} p<0.01$ vs. MCAO group. 
group, a significant decrease was seen in the level of LPO when compared with the MCAO group (Table 5).

It has been proposed that antioxidant changes reflect an altered redox balance in several pathological states. The antioxidants would be consumed in the reaction with free radicals. Therefore, the measurement of endogenous antioxidants enzymes i.e. GPx, GR, CAT and GST as well as $\mathrm{Na}^{+}-\mathrm{K}^{+}$-ATPase has been performed to estimate the amount of oxidative stress. Activities of various antioxidant enzymes and $\mathrm{Na}^{+}-\mathrm{K}^{+}$-ATPase of different groups have been listed in Tables 6, 7, 8, 9 and 10. The activity of endogenous antioxidant enzymes was decreased significantly in the MCAO group, as compared to the sham group, whereas in the $\beta$-Asarone-20 group, $\beta$-Asarone -treatment showed a significant restoration in the level of various enzymes as compared with MCAO group. The same results did occur in the $\beta$-Asarone-30 group.

A great deal of effort has been directed toward searching for a new drug that can be used for protection of cerebral ischemia-reperfusion injury. $\beta$-Asarone was used in the prevention of cerebral ischemia in this paper. Here we showed that the $\beta$-Asarone significantly improved the neurological outcome after cerebral ischemia and reperfusion in terms of neurobehavioral function in rats. At the same time, supplementation of $\beta$-Asarone significantly boosted the defense mechanism against cerebral ischemia by increasing antioxidants activity related to lesion pathogenesis. Restoration of the antioxidant homeostasis in the brain after reperfusion may help the brain recover from ischemic injury.

\section{Conclusions}

These experimental results suggest that complement $\beta$-Asarone is protective after cerebral ischemia in specific way. The administration of $\beta$-Asarone significantly reduced focal cerebral ischemic/reperfusion injury. The defense mechanism against cerebral ischemia was by increasing antioxidants activity related to lesion pathogenesis.

\section{Competing interests}

The authors declare that they have no competing interests.

\section{Authors' contributions}

GJY and LCY: designed the experiment; YYX and CYT: conducted research and drafting of the manuscript; ZXJ: acquisition of data; analysis and interpretation of data; statistical analysis; HCL: review of the manuscript; analysis and interpretation of data. All authors read and approved the final manuscript.

\section{Acknowledgement}

This work was supported by grants from the Zhejiang Key Technology Innovation Team (2012R10044-08), the Program of the Zhejiang Science and Technology (2007C23021) and the Program of the Zhejiang Province Natural Science Foundation (LQ13H280003).

Received: 5 March 2013 Accepted: 23 September 2013

Published: 25 September 2013

\section{References}

1. Kuroda S, Siesjo BK: Reperfusion damage following focal ischemia: pathophysiology and therapeutic windows. Clin Neurosci 1997, 4:199-212.

2. Gilani AU, Shah AJ, Ahmad M, Shaheen F: Antispasmodic effect of Acorus calamus Linn. is mediated through calcium channel blockade. Phytother Res 2006, 20:1080-1084.

3. Chen YZ, Wang QW, Liang Y, Fang YQ: Protective effects of beta-asarone on cultured rat cortical neurons damage induced by glutamate. Zhong Yao Cai 2007, 4:436-438.

4. Cho J, Ho KY, Kong JY: Protection of cultured rat cortical neurons from excitotoxicity by asarone, a major essential oil component in the rhizomes of Acorus gramineus. Life Sci 1998, 5:591-599.

5. Fang YQ, Fang RM, Fang GL, Jiang Y, Fu SY: Effects of beta-asarone on expression of c-fos in kindling epilepsy rat brain. Zhongguo Zhong Yao Za Zhi 2008, 5:534-536.

6. Fang YQ, Li L, Wu QD: Effects of beta-asarone on gene expression in mouse brain. Zhong Yao Cai 2003, 9:650-652.

7. Fang YQ, Wei G: To analyze if the Rhizoma Acori Tatarimowii naph-tha can go through the BBB or not with GC-MS. Zhong Yao Xin Yao Yu: Ling Chuang Yao Li 2002, 3:181-182.

8. Geng Y, Li C, Liu J, Xing G, Zhou L, Dong M, Li X, Niu Y: Beta-asarone improves cognitive function by suppressing neuronal apo-ptosis in the Beta-amyloid hippocampus injection rats. Biol Pharm Bull 2010, 5:836-843.

9. Gilani AU, Shah AJ, Ahmad M, Shaheen F: Antispasmodic effect of Acorus calamus Linn: is mediated through calcium channel blockade. Phytother Res 2006, 20:1080-1084.

10. Liu L, Fang YQ: Analysis of the distribution of $\beta$-asarone in rat hippocampus, brainstem, cortex and cerebellum with gas chromatography-mass spectrometry (GC-MS). J Med Plants Res 2011, 5:1728-1734.

11. Li C, Xing G, Dong M, Zhou L, Li J, Wang G, Zou D, Wang R, Liu J, Niu Y: Beta-asarone protection against beta-amyloid-induced neurotoxicity in PC12 cells via JNK signaling and modulation of Bcl-2 family proteins. Eur J Pharmacol 2010, 635:96-102.

12. Liu J, Li C, Xing G, Zhou L, Dong M, Geng Y, Li X, Li J, Wang G, Zou D, Niu $Y$ : Beta-asarone attenuates neuronal apoptosis induced by Beta amyloid in rat hippocampus. Yakugaku Zasshi 2010, 5:737-746.

13. Zanoli $\mathrm{P}$, Avallone $\mathrm{R}$, Baraldi M: Sedative and hypothermic effects induced by beta-asarone, a main component of Acorus calamus. Phytother Res 1998, 12:s114-s116.

14. Liu Z, Li P, Zhao D, Tang H, Guo J: Protective effect of extract of Cordyceps sinensis in middle cerebral artery occlusion-induced focal cerebral ischemia in rats. Behav Brain Funct 2010, 6:61.

15. Wang J, Liu YM, Cao W, Yao KW, Liu ZQ, Guo JY: Anti-inflammation and antioxidant effect of Cordymin, a peptide purified from the medicinal mushroom Cordyceps sinensis, in middle cerebral artery occlusioninduced focal cerebral ischemia in rats. Metab Brain Dis 2012, 27:159-165.

16. Dohare P, Garg P, Sharma U, Jagannathan NR, Ray M: Neuroprotective efficacy and therapeutic window of curcuma oil: in rat embolic stroke model. BMC Complement Altern Med 2008, 8:55.

17. Ali A, Ahmad FJ, Pillai KK, Vohora D: Evidence of the antiepileptic potential of amiloride with neuropharmacological benefits in rodent models of epilepsy and behavior. Epilepsy Behav 2004, 5:322-328.

18. Khan MR, Badar I, Siddiquah A: Prevention of hepatorenal toxicity with Sonchus asper in gentamicin treated rats. BMC Complement Altern Med 2011, 11:113.

19. Liu Z, Li P, Zhao D, Tang H, Guo J: Anti-inflammation effects of Cordyceps sinensis mycelium in focal cerebral ischemic injury rats. Inflammation 2011, 34:639-644.

20. Liu Z, Li P, Zhao D, Tang H, Guo J: Protection by vanadium, a contemporary treatment approach to both diabetes and focal cerebral ischemia in rats. Biol Trace Elem Res 2012, 145:66-70.

21. Svoboda P, Mosinger B: Catecholamines and the brain microsomal $\mathrm{Na}$, $\mathrm{K}$-adenosinetriphosphatase-I: protection against lipoperoxidative damage. Biochem Pharmacol 1981, 30:427-432.

22. Wheeler CR, Salzman JA, Elsayed NM, Omaye ST, Korte DW Jr: Automated assays for superoxide dismutase, catalase, glutathione peroxidase and glutathione reductase activity. Anal Biochem 1990, 184:193-199.

23. Jollow DJ, Mitchell JR, Zampagline N, Gillette JR: Bromobenzene induced liver necrosis: protective role of glutathione and evidence for 3,4bromobenzene as the hepatic metabolite. Pharmacology 1974, 11:151-169. 
24. Habig WH, Pabst MJ, Jakoby WB: Glutathione S-transferases: the first enzymatic step in mercapturic acid formation. J Biol Chem 1974, 249:7130-7139.

25. Jakesevic M, Aaby K, Borge Gl, Jeppsson B, Ahrné S, Molin G: Antioxidative protection of dietary bilberry, chokeberry and Lactobacillus plantarum HEAL19 in mice subjected to intestinal oxidative stress by ischemiareperfusion. BMC Complement Altern Med 2011, 11:8.

26. Traystman RJ, Kirsch JR, Koehler RC: Oxygen radical mechanisms of brain injury following ischemia and reperfusion. J Appl Physiol 1991, 71:1185-1195.

27. Bains JS, Shaw CA: Neurodegenerative disorders in humans: the role of glutathione in oxidative stress-mediated neuronal death. Brain Res Rev 1997, 25:335-338.

28. Saeed N, Khan MR, Shabbir M: Antioxidant activity, total phenolic and total flavonoid contents of whole plant extracts Torilis leptophylla L. BMC Complement Altern Med 2012, 12:221.

29. Love S: Oxidative stress in brain ischemia. Brain Pathol 1999, 9:119-131.

doi:10.1186/1472-6882-13-236

Cite this article as: Yang et al: Beta-asarone, a major component of Acorus tatarinowii Schott, attenuates focal cerebral ischemia induced by middle cerebral artery occlusion in rats. BMC Complementary and Alternative Medicine 2013 13:236.

\section{Submit your next manuscript to BioMed Central and take full advantage of:}

- Convenient online submission

- Thorough peer review

- No space constraints or color figure charges

- Immediate publication on acceptance

- Inclusion in PubMed, CAS, Scopus and Google Scholar

- Research which is freely available for redistribution 